\title{
ENTRE REVISÕES SISTEMÁTICAS E BIBLIOMETRIAS: COMO TEM SIDO MAPEADA A PRODUÇÃO ACADÊMICA EM ADMINISTRAÇÃO NO BRASIL?
}

\author{
ENTRE REVISIONES SISTEMÁTICAS Y \\ BIBLIOMETRÍAS: ¿CÓMO SE HA ASIGNADO LA \\ PRODUCCIÓN ACADÉMICA EN ADMINISTRACIÓN EN \\ BRASIL?
}

\author{
Fernanda Roda de Souza Araújo Cassundéa \\ Milka Alves Correia Barbosab \\ José Ricardo Costa Mendonçac
}

\begin{abstract}
RESUMO
Introdução: Considerando os avanços e expansão da ciência e tecnologia nas últimas décadas, diversos são os autores que tem debatido a importância do mapeamento e discussão da produção acadêmica em distintas áreas do conhecimento. Objetivo: Este estudo teve por propósito realizar uma discussão sobre as metodologias utilizadas para mapear o campo científico na área de Administração. Metodologia: Utilizou-se a base de dados da Scientific Periodicals Electronic Library (SPELL). Considerando a regra da exaustividade de Bardin (2011), foram descobertos e recuperados 83 artigos, compreendidos entre o período de 2005 a 2015. Resultados: Um grupo específico de pesquisadores vem desenvolvendo o mapeamento da produção na área desde 2005. Múltiplas bases de dados (de eventos e periódicos, nacionais e internacionais) estão sendo utilizadas para o mapeamento da produção. A Administração tem se voltado aos estudos bibliométricos, e as revisões sistemáticas e revisões sistemáticas de literatura permanecem bastante pontuais. Conclusão: Realizar a discussão das metodologias empregadas para mapear o campo científico na área de administração mostrou-se bastante relevante, principalmente porque existe, de acordo com os resultados obtidos, uma confusão conceitual entre estudos bibliométricos e revisões sistemáticas.
\end{abstract}

Descritores: Bibliometria. Estado da arte. Organização do Conhecimento.

a Doutora em Administração pela Universidade Federal de Pernambuco. Professora da Universidade Federal do Vale do São Francisco. E-mail: fernanda.roda@univasf.edu.br

b Doutora em Administração pela Universidade Federal de Pernambuco. Professora da Universidade Federal de Alagoas. E-mail: milka.correia@gmail.com

c Doutor em Administração pela Universidade Federal do Rio Grande do Sul. Professor da Universidade Federal de Pernambuco. E-mail: jrcm@ufpe.br 


\section{INTRODUÇÃO}

Considerando os avanços e expansão da ciência e tecnologia nas últimas décadas, diversos são os autores que tem debatido a importância do mapeamento e discussão da produção acadêmica nas mais distintas áreas do conhecimento (FERREIRA, 2002; VANTI, 2002; CARDOSO et al. 2005; ARAÚJO, 2006; ARAÚJO; ALVARENGA, 2011; CASSUNDÉ; CASSUNDÉ JUNIOR, 2012). Portanto, na medida em que a ciência vai se estabelecendo ao longo do tempo, ressaltando ora um aspecto, ora uma metodologia, ora determinado referencial teórico, o monitoramento dessa produção precisa ser paralelamente elaborado (SOARES; MACIEL, 2000), pois, ao identificar e explicitar os caminhos que a ciência percorreu, torna-se possível revelar 0 processo de construção do conhecimento sobre determinado tema, ou seja, identificam-se duplicações, contradições e, especialmente, lacunas, isto é, aspectos ainda não explorados.

A literatura especializada indica que os estudos bibliométricos, cienciométricos, informétricos, webmétricos e de revisão sistemática da literatura são essencialmente importantes para avaliar a ciência e os fluxos de informação já que são tipos de estudos que buscam determinar o "estado da arte" ou "estado do conhecimento". Ao que parece, "em tudo o que se refere à ciência, os indicadores bibliométricos e cienciométricos tornaram-se essenciais" (MACIAS-CHAPULA, 1998, p.134) e têm sido enaltecidos nos periódicos e eventos científicos (VANTI, 2002), pois, tem sido clara a importância de apresentar uma distribuição que informe sobre o "número de autores, trabalhos, países ou revistas que existem em cada categoria de produtividade" (PRICE, 1976, p.39).

Nesta perspectiva, os indicadores da atividade científica parecem ser, portanto, o cerne dos debates, quer na perspectiva das relações entre 0 avanço da ciência e da tecnologia, quer no progresso econômico e social (MACIAS-CHAPULA, 1998; MUGNAINNI; JANNUZZI; QUONIAM, 2004; SILVA; SANTOS; RODRIGUES, 2011; RAMOS; FARIA; FARIA, 2014). 
Assim, dada a importância dos indicadores da atividade científica, os meta-estudos tem surgido e se multiplicado especialmente no campo da Administração, cuja produção acadêmica tem crescido em quantidade nas últimas décadas (LOPES; BERNARDES, 2001; DAVEL; ALCADIPANI, 2002; CALDAS; TONELLI; LACOMBE, 2002; KIRSHBAUM; PORTO; FERREIRA, 2004), proporcionando, não somente, a consolidação da Administração enquanto área de conhecimento, mas o surgimento de indagações pertinentes à sua própria produção.

Não raro, portanto, encontrar, nos principais periódicos e eventos da área, artigos que se propõem a analisar a evolução das discussões em Administração. Assim, com a pretensão de apresentar uma perspectiva de como tais estudos têm sido desenvolvidos na área de Administração no Brasil, realizou-se uma pesquisa cuja metodologia apresenta caráter inventariante e descritivo, própria aos estudos bibliométricos (FERREIRA, 2002).

Este artigo está organizado em seis seções, incluindo esta introdutória. As seções dois e três apresentam uma discussão teórica sobre a bibliometria e a revisão sistemática, respectivamente. Em seguida são apresentados os procedimentos metodológicos. A seção cinco está subdividida em três partes onde são apresentados os resultados do estudo e a análise com relação ao mapeamento da produção científica em Administração. Fechamos o artigo com a sexta seção, tecendo as considerações finais.

\section{BIBLIOMETRIA: UMA SUBDISCIPLINA DA CIÊNCIA DA INFORMAÇÃO}

A bibliometria foi desenvolvida no início do século $X X$ em razão da "necessidade do estudo e avaliação das atividades de produção e comunicação científica" (ARAÚJO, 2006, p.12). Foram as comunicações científicas registradas, exemplificam Araújo e Alvarenga (2011), publicadas em veículos de comunicação formal ou divulgadas através de meios informais ou não convencionais, que deram origem ao que hoje são chamados de estudos bibliométricos. 
Conhecida originalmente por "bibliografia estatística", menção feita pela primeira vez, em 1922, por Edward Wyndham Hulme, referindo-se a um estudo pioneiro de Cole e Eales de 1917 em uma conferência na Universidade de Cambridge, passou a ser chamada de "bibliometria" em 1934, termo cunhado por Paul Otlet, na obra intitulada Traité de documentatión. No entanto, atribuise sua popularização a Prichard, com a publicação, em 1969, do artigo que discutia a polêmica entre bibliografia estatística e bibliometria (FONSECA, 1973; VANTI, 2002; ARAÚJO, 2006; ARAÚJO; ALVAREGA, 2011; TEIXEIRA; IWAMOTO; MEDEIROS, 2013).

Por bibliometria toma-se o conceito apresentado por Braga (1973, p.10) como sendo um conjunto de leis destinadas ao "tratamento quantitativo das propriedades e do comportamento da informação registrada". Distingue-se, portanto, da tradicional bibliografia porque esta se utiliza mais de métodos discursivos do que quantitativos (NICHOLAS; RITCHIE, 1978 apud ARAÚJO, 2006). Nesse sentido, Araújo (2006) esclarece que o ponto central da bibliometria é a utilização de métodos quantitativos na busca por uma avaliação objetiva da produção científica do conhecimento.

Outros termos como cienciometria, informetria e webmetria também têm aparecido nos estudos sobre os indicadores da atividade científica, que, segundo Vanti (2002) e Araújo (2006), são subdisciplinas ou subcampos da Ciência da Informação.

Enquanto a bibliometria analisa a produção existente de livros, documentos e periódicos; a cienciometria descreve, mediante análise de patentes e teses, os avanços em campos científicos e tecnológicos. Sobrepondo-se à bibliometria, a cienciometria pode ser compreendida como sendo o estudo dos aspectos quantitativos da ciência. A informetria, por sua vez, volta-se para a análise da geração de conhecimento, científico ou não, e distingue-se das duas anteriores em razão de não se limitar apenas à informação registrada, já que pode analisar, também, os processos de comunicação informal, inclusive a fala. Já a webmetria é mais específica e 
Fernanda Roda de Souza Araújo Cassundé, Milka Alves Correia Barbosa, José Ricardo Costa Mendonça

Entre revisões sistemáticas e bibliometrias: como tem sido mapeada a produção acadêmica em administração no Brasil?

apresenta as estatísticas de acesso dos endereços e das ferramentas de busca da internet (VANTI, 2002; TEIXEIRA; IWAMOTO; MEDEIROS, 2013).

Apresenta-se, abaixo, um quadro que elucida melhor as comparações e distinções entre bibliometria, cienciometria, informetria e webmetria.

\section{Quadro 1 - comparação das aplicações das distintas subdisciplinas da Ciência da Informação}

\begin{tabular}{|c|c|c|c|c|}
\hline $\begin{array}{c}\text { Tipologia } \\
\text { Subcampo }\end{array}$ & Bibliometria & Cienciometria & Informetria & Webmetria \\
\hline $\begin{array}{l}\text { Objeto de } \\
\text { estudo }\end{array}$ & $\begin{array}{l}\text { Livros, } \\
\text { documentos, } \\
\text { revistas, artigos, } \\
\text { autores, } \\
\text { usuários }\end{array}$ & $\begin{array}{l}\text { Disciplinas, } \\
\text { assuntos, áreas } \\
\text { e campos } \\
\text { científicos e } \\
\text { tecnológicos. } \\
\text { Patentes, } \\
\text { dissertações e } \\
\text { teses }\end{array}$ & $\begin{array}{c}\text { Palavras, } \\
\text { documentos, } \\
\text { base de dados, } \\
\text { comunicações } \\
\text { informais } \\
\text { (inclusive em } \\
\text { âmbitos não } \\
\text { científicos), } \\
\text { home pages na } \\
\text { WWW }\end{array}$ & $\begin{array}{l}\text { Sítios na WWW } \\
\text { (URL, título, tipo, } \\
\text { domínio, } \\
\text { tamanho e links), } \\
\text { motores de } \\
\text { busca }\end{array}$ \\
\hline Variáveis & $\begin{array}{l}\text { Número de } \\
\text { empréstimos } \\
\text { (circulação) e de } \\
\text { citações, } \\
\text { frequência de } \\
\text { extensão de } \\
\text { frases }\end{array}$ & $\begin{array}{c}\text { Revistas, } \\
\text { autores, } \\
\text { documentos. }\end{array}$ & $\begin{array}{l}\text { Difere da } \\
\text { cienciometria no } \\
\text { propósito das } \\
\text { variáveis, por } \\
\text { exemplo, medir } \\
\text { a recuperação, a } \\
\text { relevância, a } \\
\text { revocação }\end{array}$ & $\begin{array}{l}\text { Número de } \\
\text { páginas por sítio, } \\
\text { número de links } \\
\text { por sítio, número } \\
\text { de links que } \\
\text { remetem a um } \\
\text { mesmo sítio, } \\
\text { número de sítios } \\
\text { recuperados }\end{array}$ \\
\hline Métodos & $\begin{array}{l}\text { Ranking, } \\
\text { frequência, } \\
\text { distribuição }\end{array}$ & $\begin{array}{c}\text { Análise de } \\
\text { conjunto e de } \\
\text { correspondência, } \\
\text { co-ocorrência de } \\
\text { termos, } \\
\text { expressões, } \\
\text { palavras-chave, } \\
\text { etc. }\end{array}$ & $\begin{array}{c}\text { Modelo vetor- } \\
\text { espaço, modelos } \\
\text { booleanos de } \\
\text { recuperação, } \\
\text { modelos } \\
\text { probabilísticos, } \\
\text { linguagem de } \\
\text { processamento, } \\
\text { abordagens } \\
\text { baseadas no } \\
\text { conhecimento } \\
\end{array}$ & $\begin{array}{c}\text { Fator de impacto } \\
\text { da Web (FIW), } \\
\text { densidade dos } \\
\text { links, estratégias } \\
\text { de busca }\end{array}$ \\
\hline Objetivos & $\begin{array}{c}\text { Alocar recursos: } \\
\text { pessoas, tempo, } \\
\text { dinheiro, etc. }\end{array}$ & $\begin{array}{c}\text { Identificar } \\
\text { domínios de } \\
\text { interesse. Onde } \\
\text { os assuntos } \\
\text { estão } \\
\text { concentrados. } \\
\text { Compreender } \\
\text { como e quando } \\
\text { os cientistas se } \\
\text { comunicam }\end{array}$ & $\begin{array}{l}\text { Melhorar a } \\
\text { eficiência da } \\
\text { recuperação de } \\
\text { informação, } \\
\text { identificar } \\
\text { estruturas e } \\
\text { relações dentro } \\
\text { dos diversos } \\
\text { sistemas de } \\
\text { informação }\end{array}$ & $\begin{array}{c}\text { Avaliar o } \\
\text { sucesso de } \\
\text { determinados } \\
\text { sítios, detectar a } \\
\text { presença de } \\
\text { países, } \\
\text { instituições, } \\
\text { pesquisadores } \\
\text { na rede e } \\
\text { melhorar a } \\
\text { eficiência dos } \\
\text { motores de }\end{array}$ \\
\hline
\end{tabular}

Inf. Inf Londrina, v. 23, n. 1, p. $311-334$, jan./abr. 2018. http://www.uel.br/revistas/informacao/ 
Fernanda Roda de Souza Araújo Cassundé, Milka Alves Correia Barbosa, José Ricardo Costa Mendonça

Entre revisões sistemáticas e bibliometrias: como tem sido mapeada a produção acadêmica em administração no Brasil?

\begin{tabular}{|l|l|l|l|}
\hline & & $\begin{array}{c}\text { busca na } \\
\text { recuperação das } \\
\text { informações }\end{array}$ \\
\hline
\end{tabular}

Fonte: Adaptado de Macias-Chapula (1998) e Vanti (2002)

Vanti (2002) considera a informetria é mais ampla, abrangendo tanto a bibliometria quanto a cienciometria. Já a webmetria, Vanti (2002) a considera como sendo parte da informetria. Nesta perspectiva, a informetria pode ser entendida como um conceito guarda-chuva, envolvendo os outros três conceitos. A representação gráfica abaixo demonstra que, em um dado momento, existe uma interseção entre as subdisciplinas.

Figura 1 - Diagrama da inter-relação entre as quatro subdisciplinas

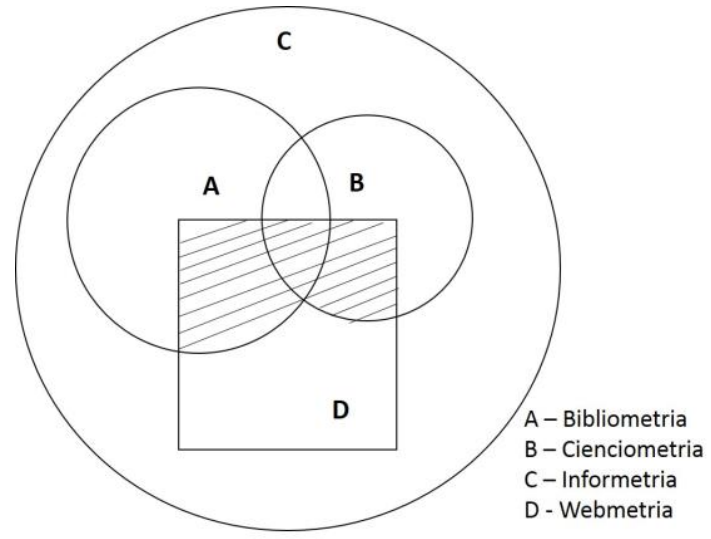

Fonte: Vanti, 2002, p.161

A distinção acima apresentada impede, acredita-se, que se crie confusões a respeito das características de cada uma das subdisciplinas da Ciência da Informação e que auxilie no entendimento do que há de ser cada uma delas. Em complemento, no sentido de melhorar a compreensão sobre cada uma, torna-se fundamental tentar estabelecer uma relação de tais subdisciplinas à utilização de aplicações concretas. Assim, Vanti (2002, p.155) apresenta, em termos genéricos, algumas possibilidades de aplicação da bibliometria, cienciometria e informetria:

- identificar as tendências e o crescimento do conhecimento em uma área; - identificar as revistas do núcleo de uma disciplina; - mensurar a cobertura das revistas secundárias; identificar os usuários de uma disciplina; - prever as tendências de publicação; - estudar a dispersão e a obsolescência da 
literatura científica; - prever a produtividade de autores individuais, organizações e países; - medir o grau e padrões de colaboração entre autores; - analisar os processos de citação e co-citação; - determinar o desempenho dos sistemas de recuperação da informação; - avaliar os aspectos estatísticos da linguagem, das palavras e das frases; - avaliar a circulação e uso de documentos em um centro de documentação; - medir o crescimento de determinadas áreas e o surgimento de novos temas (VANTI, 2002, p.155).

Seja a partir da mensuração, da compreensão da produção científica em um determinado contexto ou abordagem teórica, os estudos bibliométricos, afirmam Teixeira, Iwamoto e Medeiros (2013), valem-se da análise da produção científica por meio de categorias: produtividade científica de periódicos, autores e representação da informação (CAFÉ; BRÄSCHER, 2008). Para cada um desses campos de estudo são adotadas, respectivamente, a lei de dispersão de periódicos de Bradford, a lei de produtividade de Lotka e a lei de frequência de palavras de Zipf (ARAÚJO, 2006).

A grosso modo, estas leis sintetizam-se da seguinte forma: Bradford objetiva conhecer o núcleo de periódicos produzido em determinado tema, Lotka visa definir as maiores contribuições de pesquisadores em determinadas áreas do conhecimento e Zipf pontua a frequência com que certas palavras aparecem nos textos científicos de maneira a definir sua representatividade neste contexto (CAFÉ; BRÄSCHER, 2008, p.54).

\section{REVISÃO SISTEMÁTICA E REVISÃO SISTEMÁTICA DE LITERATURA}

Importante salientar que não foi encontrada na literatura definições distintas para revisão sistemática ou revisão sistemática de literatura. Ambos os termos são utilizados como sinônimos pelos autores, sem nenhuma diferenciação conceitual entre eles. Este estudo, portanto, também os adota como sinônimos.

As revisões sistemáticas, enquanto estratégias de pesquisa, são relativamente recentes, sendo identificadas a partir da década de 50 e muito comuns nas Ciências Médicas (GOUGH; THOMAS; OLIVER, 2012). A aproximação da revisão sistemática com as Ciências Sociais e Humanidades, 
no entanto, tem sido um esforço particular de alguns pesquisadores da área nos últimos anos (DENYER; TRANFIELD, 2009; GALVÃO; PEREIRA, 2014).

Fundamentada no Movimento de Pesquisa Baseada em Evidências, daí ser tão difundida nas Ciências Médicas, as revisões sistemáticas propõem uma reconstrução do percurso conceitual e metodológico na escolha de fontes bibliográficas. É feita realizada de acordo com procedimentos rigorosos e explícitos para que os resultados não sejam incompletos, ineficientes ou, em última instância, sem validade científica (CONTANDRIOPOULOS et al., 2010). Como o próprio nome sugere, explicam Lopes e Francolli (2008), estas revisões são sistemáticas e fazem o uso de métodos claros e rigorosos para identificação dos textos, apreciação crítica e, ainda, elaboração de sínteses de estudos relevantes. No entanto, Gough, Thomas e Oliver (2012), chamam atenção para 0 fato de que 0 crescimento em métodos não tem sido acompanhado por uma tipologia clara de definições, como consequência, o resultado é uma complexa teia de terminologia.

Neste sentido, uma distinção importante merece ser feita. As revisões sistemáticas são metodologicamente mais elaboradas e criteriosas que as revisões de literatura tradicionais.

\begin{abstract}
A revisão de literatura tradicional tipicamente apresenta resultados de investigação relativos a um tópico de interesse [do investigador]. Resumem o que é conhecido sobre esse tópico sem explicarem os critérios utilizados para identificar e incluir esses estudos nem justificar o motivo de alguns estudos serem descritos e discutidos, e outros não. Assim, estudos potencialmente relevantes podem não ter sido incluídos na revisão de literatura por o autor não ter conhecimento deles ou, conhecendo-os, decidir não os incluir por razões que não explica. Se o processo de identificação das fontes bibliográfica não for explícita, consistente e rigorosa, não é possível avaliar a adequação dessas fontes ao estudo (GOUGH, 2011 apud RAMOS; FARIA; FARIA, 2014, p.20).
\end{abstract}

As revisões sistemáticas empregam, portanto, uma metodologia de pesquisa com alto rigor científico, em que se objetiva minimizar o viés da literatura na medida em que é realizada uma recolha exaustiva dos textos 
publicados sobre o tema que se pretende analisar (TRANFIELD; DENYER; SMART, 2003; THORPE et al., 2005).

Cabe salientar que três etapas precisam ser consideradas antes de iniciar uma revisão sistemática, conforme recomendam Sampaio e Mancini (2007), quais sejam: 1 - definição do objetivo da revisão; 2 - identificação da literatura; e 3 - seleção dos possíveis estudos a serem incluídos. É preciso destacar também que uma revisão sistemática deve seguir a mesma estrutura de um artigo original, tal qual como comumente é escrito, com introdução, métodos, resultados e discussão.

\section{PROCEDIMENTOS METODOLÓGICOS}

Os critérios de seleção dos artigos para este estudo seguiram os procedimentos de coleta e de análise definidos por Tonelli et al. (2003), que consideraram os mais citados meta-estudos nas diversas áreas do Enanpad, a exemplo de Vieira (1998) e Perin et al. (2000).

A base de dados escolhida como fonte de pesquisa para esta discussão é a da Scientific Periodicals Electronic Library (SPELL). O SPELL é, atualmente, o principal sistema de indexação, pesquisa e disponibilização gratuita da produção científica em Administração no país. Para fazer parte da base do SPELL, o periódico precisa atender, dentre outras, as seguintes condições: estar classificado no Qualis de Administração, Contabilidade e Turismo no estrato B5 ou superior e ser periódico genuíno da área de Administração, Contabilidade e Turismo, o que exclui revistas de outras áreas ou multidisciplinares. O SPELL também foi escolhido em função de um de seus objetivos ser a facilitação da produção de estatísticas de uso e acesso aos periódicos, bem como de análises bibliométricas e cientométricas. Dessa maneira, o SPELL possuía, à época da realização desse estudo, 92 periódicos indexados, disponibilizando mais de 30.500 artigos para consulta em seu acervo; 
A definição do corpus seguiu a regra da exaustividade de Bardin (2011). Nesse sentido, não foi estabelecido um corte temporal, a priori, para validar os artigos recuperados na busca;

O critério de busca levou em consideração categorias analíticas que deveriam constar como palavras-chave no artigo: bibliometria; bibliométrico; revisão sistemática; revisão sistemática da literatura; estado da arte e estado do conhecimento. Todos os textos que emergiram a partir dos critérios de busca estabelecidos foram considerados. Assim, essa etapa finalizou com 124 artigos completos;

Foram analisados os periódicos de cada um dos 124 artigos selecionados na etapa anterior no sentido de identificar aqueles cujo foco e escopo, prioritariamente, relacionavam-se à divulgação da produção científica na área de Administração, excluindo-se, portanto, os periódicos relacionados às áreas de Contabilidade e Turismo. Essa etapa finalizou com 83 artigos completos e selecionados como corpus do estudo. A recuperação dos artigos foi realizada no mês de julho de 2015.

Como técnica de análise, optou-se pela análise de conteúdo (AC) apresentada por Bardin (2011, p.44), e entendida como um

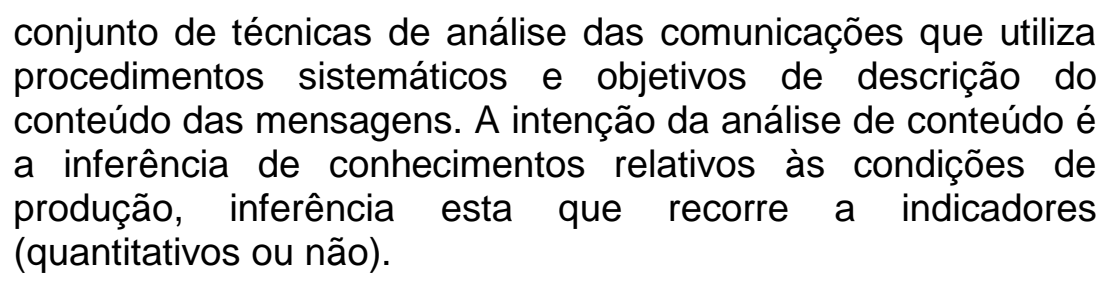

A seção a seguir apresenta a análise dos artigos recuperados.

\section{ANÁLISE E DISCUSSÃO DOS RESULTADOS}

Uma análise geral pode ser feita a partir dos artigos recuperados. A tabela 1 abaixo apresenta o total de artigos recuperados, a média de acessos, a média de downloads e o intervalo de publicação para cada uma das categorias analíticas estabelecidas na busca. 
Fernanda Roda de Souza Araújo Cassundé, Milka Alves Correia Barbosa, José Ricardo Costa Mendonça

Entre revisões sistemáticas e bibliometrias: como tem sido mapeada a produção acadêmica em administração no Brasil?

Tabela 1 - Total de artigos recuperados, a média de acessos, a média de downloads e o intervalo de publicação

\begin{tabular}{c|c|c|c|c}
\hline & $\begin{array}{c}\text { Revisão Sistemática e } \\
\text { Revisão Sistemática da } \\
\text { Literatura }\end{array}$ & $\begin{array}{c}\text { Estado da } \\
\text { arte }\end{array}$ & Bibliometria & $\begin{array}{c}\text { Estado do } \\
\text { conhecimento }\end{array}$ \\
\hline $\begin{array}{c}\text { Total de } \\
\text { artigos } \\
\text { recuperados }\end{array}$ & 03 & 09 & 71 & - \\
\hline $\begin{array}{c}\text { Média de } \\
\text { acessos }\end{array}$ & 654 & 909 & 668 & - \\
\hline $\begin{array}{c}\text { Média de } \\
\text { downloads }\end{array}$ & 294 & 618 & 307 & - \\
\hline $\begin{array}{c}\text { Intervalo de } \\
\text { publicação }\end{array}$ & $2011-2014$ & $2005-2015$ & $2008-2015$ & - \\
\hline
\end{tabular}

Fonte: os autores

Os estudos sobre os indicadores na área de Administração começaram a aparecer apenas a partir de 2005, sendo, portanto, relativamente recentes. A bibliometria é a que mais se destaca em termos de quantidade de artigos recuperados (71), no entanto, são os estudos classificados como estado da arte que apresentam maior média de acessos em termos de visualização do resumo (909) e maior média de download do arquivo (618). Ainda são incipientes os trabalhos que se propõem a realizar revisões sistemáticas e revisões sistemáticas da literatura.

\subsection{CONTRIBUIÇÃO DAS REVISÕES SISTEMÁTICAS E REVISÕES SISTEMÁTICAS DA LITERATURA PARA O MAPEAMENTO DA PRODUÇÃo CIENTÍFICA EM ADMINISTRAÇÃO}

Foram encontrados, para a busca relacionada as palavras-chave "revisão sistemática" e "revisão sistemática da literatura", apenas três publicações de acordo com os critérios estabelecidos.

Os trabalhos foram publicados em três revistas distintas (classificadas como B1 ou B4) entre os anos de 2011 e 2014. Todos os textos apresentam coautoria e, ao todo, onze pesquisadores foram os responsáveis por essas produções, com uma média de, aproximadamente, quatro autores por artigo. Não houve predominância de autores.

Não há prevalência com relação a base de dados utilizada nos artigos, sendo identificadas as seguintes bases: Compendex, EbscoHost, Scielo, 
Scopus e Web of Science. Foram consultados também os anais de alguns dos principais eventos científicos da área, quais sejam: EnANPAD (Encontro da Associação Nacional dos Programas de Pós-Graduação em Administração), EnAPG (Encontro de Administração Pública da ANPAD), Enegep (Encontro Nacional de Engenharia de Produção), Simpep (Simpósio de Engenharia de Produção) e Simpoi (Simpósio de Administração da Produção, Logística e Operações Internacionais). O Banco de Teses e Dissertações da Capes também foi utilizado.

Os artigos de revisão sistemática e revisão sistemática da literatura analisaram, em conjunto, 83 trabalhos publicados no período de 1996 a 2012, totalizando 17 anos de cobertura das produções científicas.

\subsection{CONTRIBUIÇÃO DOS ESTUDOS DO ESTADO DA ARTE PARA O MAPEAMENTO DA PRODUÇÃo CIENTÍFICA EM AdMINISTRAÇÃo}

Vinte e dois pesquisadores publicaram, em oito periódicos distintos, nove artigos sobre o estado da arte em Administração. A classificação do QUALIS/CAPES é de B1 a B3, com predominância para as revistas B1 (4 periódicos). A primeira publicação sobre o estado da arte apareceu em 2005 na REAd - Revista Eletrônica de Administração. Os artigos são produzidos, em sua maioria, em coautoria, apresentando valor modal de 2 para quantidade de autores por artigo. Assim como as revisões sistemáticas e revisões sistemáticas da literatura, não há predominância de autores para os estudos de estados da arte.

Embora tenham sido utilizadas múltiplas bases de dados por artigo, não há predominância de nenhuma delas. Os autores pesquisaram tanto em periódicos quanto em anais de eventos, com destaque para o evento da ANPAD, O EnANPAD. Foram cobertos os últimos 45 anos de publicações, através da análise de 159 artigos.

É do estado da arte que se tem o artigo com o maior número de acessos (5863) e também de downloads (4903). 
Fernanda Roda de Souza Araújo Cassundé, Milka Alves Correia Barbosa, José Ricardo Costa Mendonça

Entre revisões sistemáticas e bibliometrias: como tem sido mapeada a produção acadêmica em administração no Brasil?

\subsection{CONTRIBUIÇÃO DA BIBLIOMETRIA PARA O MAPEAMENTO DA PRODUÇÃO CIENTÍFICA EM ADMINISTRAÇÃo}

Foram os estudos bibliométricos que mais contribuíram, em termos de quantidade, para o mapeamento da produção em Administração. Ao todo, 71 artigos apresentaram propostas bibliométricas a partir do ano de 2008. Foram analisados, aproximadamente, 21.537 artigos entre o período de 1945 e 2013 (69 anos de cobertura da produção acadêmica da área).

Assim como as revisões sistemáticas e estado da arte, os estudos bibliométricos, em sua maioria, são elaborados em coautoria (média de 3 autores/artigo), no entanto, foi possível identificar um grupo específico de pesquisadores. A tabela 2 abaixo apresenta, em ordem alfabética, os principais autores (com dois ou mais artigos publicados).

Tabela 2 - Principais autores (por ordem alfabética) dos estudos bibliométricos

\begin{tabular}{|l|c|}
\hline \multicolumn{1}{|c|}{ Primeiro Autor } & $\begin{array}{c}\text { Qtd de } \\
\text { artigos } \\
\text { publicados }\end{array}$ \\
\hline Aline Botelho Schneider Venson & 2 \\
\hline Cristiana Fernandes de Muylder & 2 \\
\hline $\begin{array}{l}\text { Fernanda Roda de Souza Araújo } \\
\text { Cassundé }\end{array}$ & 2 \\
\hline Henrique César Melo Ribeiro & 6 \\
\hline Jordana Marques Kneipp & 2 \\
\hline
\end{tabular}

Fonte: os autores.

A tabela 3 abaixo apresenta os periódicos que publicaram, a partir de 3 artigos, os estudos bibliométricos. O destaque é para a Revista Eletrônica de Estratégia \& Negócios (B3 no Qualis/CAPES), com sete diferentes publicações. São os periódicos classificados como B3 que, ao todo, mais publicaram estudos bibliométricos (23 artigos).

Tabela 3 - Principais periódicos com publicação de bibliometria

\begin{tabular}{|l|c|c|}
\hline \multicolumn{1}{|c|}{ Periódico } & $\begin{array}{c}\text { Qtd de } \\
\text { artigos } \\
\text { publicados }\end{array}$ & $\begin{array}{c}\text { Qualis/ } \\
\text { CAPES }\end{array}$ \\
\hline Revista Eletrônica de Estratégia \& Negócios & 7 & B3 \\
\hline Revista de Administração da UFSM & 4 & B1 \\
\hline Revista de Ciências da Administração & 4 & B1 \\
\hline
\end{tabular}


Fernanda Roda de Souza Araújo Cassundé, Milka Alves Correia Barbosa, José Ricardo Costa Mendonça

Entre revisões sistemáticas e bibliometrias: como tem sido mapeada a produção acadêmica em administração no Brasil?

\begin{tabular}{|l|c|c|}
\hline Administração: Ensino e Pesquisa & 3 & B3 \\
\hline Revista de Administração e Inovação & 3 & B1 \\
\hline Revista de Administração Mackenzie & 3 & B1 \\
\hline Revista de Gestão Social e Ambiental & 3 & B2 \\
\hline Revista Organizações em Contexto & 3 & B2 \\
\hline $\begin{array}{l}\text { Revista Pensamento Contemporâneo em } \\
\text { Administração }\end{array}$ & 3 & B2 \\
\hline
\end{tabular}

Fonte: os autores.

Foi analisado o número total de downloads em razão da classificação dos periódicos no Qualis/CAPES (tabela 4). Importante notar que, apesar de serem as revistas classificadas como B3 com maior contribuição em termos de quantidade de publicação, tais artigos ainda não são os mais lidos. São os artigos das revistas B2 que apresentam o maior número de downloads realizado (7.588).

Tabela 4 - Classificação Qualis/CAPES x número de downloads

\begin{tabular}{|c|c|}
\hline Qualis/CAPES & $\begin{array}{c}\text { Número } \\
\text { de } \\
\text { downloads }\end{array}$ \\
\hline A2 & 605 \\
\hline B1 & 6977 \\
\hline B2 & 7588 \\
\hline B3 & 6567 \\
\hline B5 & 53 \\
\hline
\end{tabular}

Fonte: os autores.

Em relação à classificação Qualis/CAPES, tem-se que as revistas avaliadas como B3 são maioria entre os periódicos (14 periódicos distintos). Merece atenção o fato de nenhuma revista $A 1$ aparecer na lista e de apenas duas A2 serem listadas (tabela 5). Ao todo, 36 periódicos publicaram estudos bibliométricos.

Tabela 5 - Classificação Qualis/CAPES dos periódicos que publicaram bibliometria

\begin{tabular}{|c|c|l|}
\hline $\begin{array}{c}\text { Classificação } \\
\text { Qualis/CAPES }\end{array}$ & $\begin{array}{c}\text { Qtd de } \\
\text { periódicos }\end{array}$ & \multicolumn{1}{c|}{ Periódicos } \\
\hline A2 & 2 & $\begin{array}{l}\text { Brazilian Business Review } \\
\text { Revista de Administração de Empresas }\end{array}$ \\
\hline B1 & 7 & $\begin{array}{l}\text { Cadernos EBAPE.BR } \\
\text { REAd. Revista Eletrônica de Administração } \\
\text { Revista de Administração da UFSM }\end{array}$ \\
\hline
\end{tabular}


Fernanda Roda de Souza Araújo Cassundé, Milka Alves Correia Barbosa, José Ricardo Costa Mendonça

Entre revisões sistemáticas e bibliometrias: como tem sido mapeada a produção acadêmica em administração no Brasil?

\begin{tabular}{|c|c|c|}
\hline & & $\begin{array}{l}\text { Revista de Administração da Unimep } \\
\text { Revista de Administração e Inovação } \\
\text { Revista de Administração Mackenzie } \\
\text { Revista de Ciências da Administração }\end{array}$ \\
\hline B2 & 12 & $\begin{array}{l}\text { InternexT - Revista Eletrônica de Negócios } \\
\text { Internacionais da ESPM } \\
\text { Revista Brasileira de Estratégia } \\
\text { Revista Brasileira de Inovação } \\
\text { Revista Brasileira de Marketing } \\
\text { Revista de Gestão Social e Ambiental } \\
\text { Revista Economia \& Gestão } \\
\text { Revista Eletrônica de Ciência Administrativa } \\
\text { Revista Gestão \& Planejamento } \\
\text { Revista Gestão \& Tecnologia } \\
\text { Revista Gestão Organizacional } \\
\text { Revista Organizações em Contexto } \\
\text { Revista Pensamento Contemporâneo em } \\
\text { Administração }\end{array}$ \\
\hline B3 & 14 & $\begin{array}{l}\text { Administração Pública e Gestão Social } \\
\text { Administração: Ensino e Pesquisa } \\
\text { Amazônia, Organizações e Sustentabilidade } \\
\text { Future Studies Research Journal: Trends and } \\
\text { Strategies } \\
\text { Gestão e Sociedade } \\
\text { Perspectivas em Gestão \& Conhecimento } \\
\text { Revista da Micro e Pequena Empresa } \\
\text { Revista de Economia e Administração } \\
\text { Revista de Empreendedorismo e Gestão de } \\
\text { Pequenas Empresas } \\
\text { Revista de Gestão } \\
\text { Revista de Gestão e Projetos } \\
\text { Revista de Negócios } \\
\text { Revista Eletrônica de Estratégia \& Negócios } \\
\text { Revista lbero-Americana de Estratégia }\end{array}$ \\
\hline B5 & 1 & Gestão \& Regionalidade \\
\hline
\end{tabular}

Fonte: os autores.

Os estudos bibliométricos, embora tenham tido um início de publicações constante (2008-2010), a partir de 2011 apresentam um crescente de produção. Este cenário parece refletir a importância que a academia tem dado à bibliometria devido a necessidade de se compreender o desenvolvimento da ciência.

Tabela 6 - Ano de publicação dos estudos bibliométricos

\begin{tabular}{|c|c|}
\hline Ano & $\begin{array}{c}\text { Qtd de } \\
\text { publicações }\end{array}$ \\
\hline 2008 & 2 \\
\hline
\end{tabular}


Entre revisões sistemáticas e bibliometrias: como tem sido mapeada a produção acadêmica em administração no Brasil?

\begin{tabular}{|c|c|}
\hline 2009 & 2 \\
\hline 2010 & 2 \\
\hline 2011 & 10 \\
\hline 2012 & 12 \\
\hline 2013 & 21 \\
\hline 2014 & 19 \\
\hline 2015 & 3 \\
\hline
\end{tabular}

Fonte: os autores.

Múltiplas bases de dados (de eventos e periódicos, nacionais e internacionais) foram utilizadas pelos pesquisadores para construção os estudos bibliométricos. Onze bases de dados se destacaram em termos de utilização, sendo a maioria de origem estrangeira, divulgam essencialmente a produção científica internacional. Genuinamente nacionais, tem-se o SPELL, 0 Portal de Periódicos da CAPES e o SciELO. A tabela 7 abaixo apresenta as bases de dados mais utilizadas.

\section{Tabela 7 - Sobre as bases de dados utilizadas}

\begin{tabular}{|c|c|c|}
\hline Base de dados & Utilização & Sobre a base de dados \\
\hline Engineering Village & 2 & $\begin{array}{l}\text { Esta base de dados é elaborada pelo grupo } \\
\text { Elsevier e disponibiliza acesso a } 12 \\
\text { literaturas de engenharia e bancos de } \\
\text { dados de patentes, oferecendo cobertura a } \\
\text { partir de uma ampla gama de fontes } \\
\text { confiáveis de engenharia. }\end{array}$ \\
\hline Science Direct & 2 & $\begin{array}{l}\text { Esta base de dados é elaborada pelo grupo } \\
\text { Elsevier e disponibiliza artigos em mais de } \\
2.500 \text { periódicos e aproximadamente } 33.00 \\
\text { títulos de livros nas áreas de: Ciências } \\
\text { Físicas e Engenharia, Ciências da Vida, } \\
\text { Ciências da Saúde, Ciências Sociais e } \\
\text { Humanas. }\end{array}$ \\
\hline Emerald & 3 & $\begin{array}{l}\text { Esta base de dados faz parte do Emerald } \\
\text { Group Publishing. Disponibiliza possui mais } \\
\text { de } 80.000 \text { artigos em mais de } 200 \\
\text { periódicos nas seguintes áreas: Educação, } \\
\text { Engenharia, Marketing. }\end{array}$ \\
\hline $\begin{array}{l}\text { Spell - Scientific } \\
\text { Periodicals Electronic } \\
\text { Library }\end{array}$ & 4 & $\begin{array}{l}\text { A ANPAD - Associação Nacional dos } \\
\text { Programas de Pós-Graduação em } \\
\text { Administração é a responsável por esta } \\
\text { base de dados. Iniciado em 2012, o Spell } \\
\text { concentra, inicialmente, a produção } \\
\text { científica nacional das áreas de } \\
\text { Administração, Contabilidade e Turismo. }\end{array}$ \\
\hline Wiley Online Library & 4 & Wiley Library Online hospeda uma coleção \\
\hline
\end{tabular}


Fernanda Roda de Souza Araújo Cassundé, Milka Alves Correia Barbosa, José Ricardo Costa Mendonça

Entre revisões sistemáticas e bibliometrias: como tem sido mapeada a produção acadêmica em administração no Brasil?

\begin{tabular}{|c|c|c|}
\hline & & $\begin{array}{l}\text { multidisciplinar nas áreas de Ciências da } \\
\text { Saúde, Ciências Físicas, Ciências Sociais, } \\
\text { e Ciências Humanas. Oferece acesso } \\
\text { contínuo e integrado para mais de } 6 \\
\text { milhões de artigos em mais de } 1.500 \\
\text { revistas, mais de } 16.000 \text { livros on-line, e } \\
\text { centenas de obras de referência, } \\
\text { protocolos laboratoriais e bancos de dados. } \\
\text { Disponível em } 13 \text { idiomas. }\end{array}$ \\
\hline Proquest & 5 & $\begin{array}{l}\text { Bancos de dados da ProQuest é uma fonte } \\
\text { para jornais acadêmicos, jornais, relatórios, } \\
\text { juntamente com milhões de páginas de } \\
\text { fontes primárias históricas digitalizadas e } \\
\text { mais de } 450 \text { mil ebooks. }\end{array}$ \\
\hline $\begin{array}{l}\text { Portal de Periódicos da } \\
\text { CAPES }\end{array}$ & 6 & $\begin{array}{l}\text { O Portal de Periódicos da Capes oferece } \\
\text { acesso a textos completos disponíveis em } \\
\text { mais de } 37 \text { mil publicações periódicas, } \\
\text { internacionais e nacionais, e à diversas } \\
\text { bases de dados que reúnem desde } \\
\text { referências e resumos de trabalhos } \\
\text { acadêmicos e científicos até normas } \\
\text { técnicas, patentes, teses e dissertações } \\
\text { dentre outros tipos de materiais, cobrindo } \\
\text { todas as áreas do conhecimento. Inclui } \\
\text { também uma seleção de importantes } \\
\text { fontes de informação científica e } \\
\text { tecnológica de acesso gratuito na web. }\end{array}$ \\
\hline $\begin{array}{l}\text { SciELO - Scientific } \\
\text { Electronic Library Online }\end{array}$ & 6 & $\begin{array}{l}\text { Criado em 1999, esta base de dados } \\
\text { disponibiliza "coleções em acesso aberto } \\
\text { de periódicos científicos avaliados pelos } \\
\text { pares, publicadas por instituições nacionais } \\
\text { dos países ibero-americanos e da África do } \\
\text { Sul. As coleções são multidisciplinares e } \\
\text { em diversos idiomas" (PACKER; } \\
\text { MENEGHINI, 2014, p.15). Foram } \\
\text { publicados até julho de } 2015 \\
\text { aproximadamente 458mil artigos. }\end{array}$ \\
\hline EBSCOhost & 11 & $\begin{array}{l}\text { Esta base de dados fornece um serviço } \\
\text { pago de pesquisa on-line com } 375 \text { bancos } \\
\text { de dados de texto completo, uma coleção } \\
\text { de mais de } 600.000 \text { ebooks, índices por } \\
\text { assunto, referências médicas, e uma } \\
\text { variedade de arquivos digitais históricos. }\end{array}$ \\
\hline Scopus & 11 & $\begin{array}{l}\text { Scopus é uma base de dados bibliográfica } \\
\text { que contém resumos e citações de artigos } \\
\text { de periódicos acadêmicos. Abrange cerca } \\
\text { de } 22.000 \text { títulos de } 5.000 \text { editoras, dos } \\
\text { quais } 20.000 \text { são revistas e jornais } \\
\text { científicos (ciências médicas e sociais, } \\
\text { incluindo artes e humanidades). E } \\
\text { propriedade da Elsevier e está disponível }\end{array}$ \\
\hline
\end{tabular}

Inf. Inf Londrina, v. 23, n. 1, p. $311-334$, jan./abr. 2018.

http://www.uel.br/revistas/informacao/ 
Entre revisões sistemáticas e bibliometrias: como tem sido mapeada a produção acadêmica em administração no Brasil?

\begin{tabular}{|l|l|l|}
\hline & on-line por assinatura. \\
\hline & $\begin{array}{l}\text { Criada pela Thomson Reuters, esta base } \\
\text { de dados disponibiliza artigos de } \\
\text { periódicos, patentes, sites, anais de } \\
\text { eventos, material de acesso aberto - todos } \\
\text { podem ser acessados através de uma } \\
\text { interface, usando uma variedade de } \\
\text { Web of Science } \\
\text { feramentas de pesquisa e análise. } \\
\text { Abrange as Ciências, Ciências Sociais, } \\
\text { Artes e Humanidades. Fornece conteúdo e } \\
\text { ferramentas para acessar, analisar e } \\
\text { gerenciar informações de pesquisa } \\
\text { bibliográfica. Vários bancos de dados } \\
\text { podem ser pesquisados simultaneamente. } \\
\text { As bases de dados combinada incluem o } \\
\text { seguinte: 23.000 revistas acadêmicas e } \\
\text { científicas, 23.000.000 patentes, 110.000 } \\
\text { artigos de conferências, 9.000 sites, } \\
\text { cobrindo do ano de 1900 até os dias atuais. }\end{array}$ \\
\hline
\end{tabular}

Fonte: os autores.

Os anais dos eventos também foram utilizados como fonte de pesquisa para a construção dos artigos bibliométricos. O destaque é para o EnANPAD, o Encontro da Associação Nacional dos Programas de Pós-Graduação em Administração, que ocorre periodicamente desde 1997, sendo considerado, atualmente, como segundo maior evento científico da área de Administração do mundo.

\section{CONSIDERAÇÕES FINAIS}

Este estudo se propôs a analisar como a Administração tem mapeado a sua produção acadêmica. Para o atingimento dos objetivos propostos foi utilizada a base de dados da SPELL. Os critérios de busca foram definidos a partir de palavras-chave, tais como: bibliometria, bibliométrico, revisão sistemática, revisão sistemática da literatura, estado da arte e estado do conhecimento. Foram analisados, ao todo, 83 artigos através da análise de conteúdo de Bardin (2011).

Realizar a discussão das metodologias empregadas para mapear 0 campo científico na área de administração mostrou-se bastante relevante, principalmente porque existe, de acordo com os resultados obtidos, uma 
confusão conceitual entre estudos bibliométricos e revisões sistemáticas. É importante que os pesquisadores da área compreendam que, embora a bibliometria seja parte integrante de estudos de revisão sistemática, a metodologia é bem mais ampla e que existe uma série de elementos imbuídos nas fases da revisão sistemática que necessitam ser atendidas, sendo importante elaborar um protocolo de pesquisa a partir de critérios definidos previamente.

Embora os pesquisadores tenham produzido mais estudos bibliométricos para mapear a produção da área, parecem ser os estados da arte que mais interessam aos leitores dos artigos, dada as estatísticas sobre acesso e download dos artigos. Importante destacar que os estudos classificados como "estado da arte" (e também "estado do conhecimento") são, a princípio, bibliométricos ou revisões sistemáticas. A não definição adequada dos mesmos parece sugerir uma imprecisão conceitual dos autores.

Considerando a jovialidade da área, acredita-se que as revisões sistemáticas deveriam aparecer com mais constância, mas não aparecem. Questionamentos surgem em função desse cenário: por que não são produzidas mais revisões sistemáticas? Os pesquisadores não dão a devida importância? Não apresentam expertise para isso? Dos resultados obtidos neste estudo tem-se que há um certo sentido que o foco dos estudos brasileiros seja na bibliometria, uma vez que ela surgiu há mais tempo e, por sua vez, as revisões sistemáticas ainda estão começando. O que se tem percebido, no entanto, é que o objetivo das revisões sistemáticas de literatura não é bem compreendido pelos pesquisadores, sendo frequentemente considerada o mesmo que um estudo bibliométrico.

Outros questionamentos também surgem quando se analisa 0 Qualis/CAPES das revistas que publicaram estudos sobre o desenvolvimento da ciência. Verificou-se que, embora os periódicos A1 e A2 sejam indicativos de melhor qualidade de publicação, não publicam (ou não têm o costume de publicar) estudos bibliométricos. Por que? Por que não há submissão? Não há espaço no periódico? Não faz parte do escopo? Ou, como sugere Mattos 
Fernanda Roda de Souza Araújo Cassundé, Milka Alves Correia Barbosa, José Ricardo Costa Mendonça

Entre revisões sistemáticas e bibliometrias: como tem sido mapeada a produção acadêmica em administração no Brasil?

(2004, p.3), "a bibliometria, da forma como tem sido usada (...) no mínimo põe em questão a metodologia já tradicional na academia"?

Como pesquisas futuras sugere-se analisar sob quais temáticas, dentro da área da Administração, foram realizados os estudos, além disso, qual foi o resultado encontrado. Essa discussão pode ser ampliada apresentando vantagens e desvantagens de cada um dos métodos empregados sob o ponto de vista dos pesquisadores brasileiros. Nesta perspectiva, espera-se que 0 seguinte questionamento possa ser respondido: será que a escolha da metodologia pelos pesquisadores brasileiros tem contribuído para que eles atinjam o objetivo ao realizar esse tipo de pesquisa?

\section{REFERÊNCIAS}

ARAÚJO, C. A. Bibliometria: evolução histórica e questões atuais. Em Questão. Porto Alegre, v. 12, n. 1, p. 11-32, jan./jun. 2006.

ARAÚJO, R. F.; ALVARENGA, L. A bibliometria na pesquisa científica da pósgraduação brasileira de 1987 a 2007. Ciência da Informação, Florianópolis, v. 16, n. 31, p. 51-70, 2011.

BARDIN, L. Análise de conteúdo. São Paulo: Edições 70, 2011.

BRAGA, G. Relações bibliométricas entre a frente de pesquisa (research front) e revisões da literatura: estudo aplicado à Ciência da Informação. Ciência da Informação, v. 2, n. 1, p. 9-26, 1973.

CAFÉ, L.; BRÄSCHER, M. Organização da informação e bibliometria. Ciência da Informação, Florianópolis, n. esp., 1ำ sem. 2008.

CALDAS, M.; TONELLI, M. J.; LACOMBE, B. M. B. Espelho, Espelho Meu: Metaestudo da Produção Científica em Recursos Humanos nos ENANPADs da Década de 90. In: ENCONTRO DOS PROGRAMAS DE PÓS-GRADUAÇÃO EM ADMINISTRAÇÃO, 16., 2002, Campinas, SP. Anais... Campinas, São Paulo: Anpad, 2002.

CARDOSO, R. L.; MENDONÇA NETO, O. R.; RICCIO, E. L.; SAKATA, M. C. G. Pesquisa científica em contabilidade entre 1990 e 2003. Revista de Administração de Empresas, São Paulo, v. 45, n. 2, p. 34-45, abr/jun 2005.

CASSUNDÉ, F. R.; CASSUNDÉ JUNIOR, N. O estado do conhecimento sobre educação a distância (EAD) em Administração: por onde caminham os artigos? 
Entre revisões sistemáticas e bibliometrias: como tem sido mapeada a produção acadêmica em administração no Brasil?

Revista Gestão e Planejamento, Salvador, v. 13, n. 2, p.366-374, maio/ago. 2012.

CONTANDRIOPOULOS, D. et al. Knowledge exchange processes in organisations and policy arenas: a narrative systematic review of the literature. Millbank Quarterly, v. 88, n. 4, p. 444-483, Dec. 2010.

DAVEL, E.; ALCADIPANI, R. Estudos críticos em Administração: reflexões e constatações sobre produção brasileira. In: Encontro de Estudos Organizacionais, 2002, Recife. Anais... Recife: Observatório da Realidade Organizacional: PROPAD/UFPE: ANPAD, 2002.

DENYER, D.; TRANFIELD, D. Producing a systematic review. In: BUCHANAN, D. A.; BRYMAN, A. The SAGE handbook of organizational research methods. Los Angeles; London: SAGE, 2009.

FERREIRA, N. S. A. As pesquisas denominadas "estado da arte". Educação \& Sociedade, ano XXIII, n. 79, Agosto/2002.

FONSECA, E. N. Bibliografia estatística e bibliometria: uma reivindicação de prioridades. Ciência da Informação, Brasília, v. 2, n.1, p. 5-7, 1973.

GALVÃO, T. F.; PEREIRA, M. G. Revisões sistemáticas da literatura: passos para sua elaboração. Epidemiol. Serv. Saúde, Brasília, v. 23, n. 1, jan./mar. 2014.

GOUGH, D.; THOMAS, J.; OLIVER, S. Clarifying differences between review de- signs and methods. Systematic Reviews, v. 1, n. 1, p. 28, 2012.

KIRSHBAUM, C.; PORTO, E. C.; FERREIRA, F. C. M. Neo-Institucionalismo na produção acadêmica em Administração. RAE-Eletrônica, v.3, n.1, maio/Jun. 2004.

LOPES, A. L.; FRACOLLI, L. A.. Revisão sistemática de literatura e metassíntese qualitativa: considerações sobre sua aplicação na pesquisa em enfermagem. Texto Contexto Enferm., Florianópolis, v. 17, n. 4, p.771-778, out./dez. 2008.

LOPES, H. E. G.; BERNARDES, P. Ampliando a análise da produção científica em administração: o indutivo versus o dedutivo. Economia \& Gestão, v.1, n.2, Jul./Dez. 2001.

MACIAS-CHAPULA, C. A. O papel da informetria e da cienciometria e sua perspectiva nacional e internacional. Ciência da Informação, Brasília, v. 27, n. 2, p. 134-140, maio/ago. 1998. 
Entre revisões sistemáticas e bibliometrias: como tem sido mapeada a produção acadêmica em administração no Brasil?

MATTOS, P. L. C. L. Bibliometria: a metodologia acadêmica convencional em questão. RAE Eletrônica, São Paulo, v. 3, n. 2, art. 26, jul./dez. 2004.

MUGNAINI, R.; JANNUZZI, P. M.; QUONIAM, L. Indicadores bibliométricos da produção brasileira: uma análise a partir da base Pascal. Ciência da Informação, Brasília, v. 33, n. 2, p. 123-131, maio/ago. 2004.

PACKER, A. L.; MENEGHINI, R. O SciELO aos 15 anos: raison d'être, avanços e desafios para o futuro. In: PACKER, A.L., et al. SciELO - 15 Anos de Acesso Aberto: um estudo analítico sobre Acesso Aberto e comunicação científica. Paris: UNESCO, 2014.

PERIN, M. G. et al. A pesquisa survey em artigos de marketing nos ENANPADs da década de 90. In: ENCONTRO DOS PROGRAMAS DE PÓSGRADUAÇÃO EM ADMINISTRAÇÃO (ENANPAD), 24., 2000, Florianópolis (SC). Anais... Florianópolis: ANPAD, 2000.

PRICE, D. S. O desenvolvimento da ciência: análise histórica, filosófica, sociológica e econômica. Rio de Janeiro: Livros Técnicos e Científicos, 1976.

RAMOS, A.; FARIA, P. M.; FARIA, Á. Revisão sistemática de literatura: contributo para a inovação na investigação em Ciências da Educação. Revista Diálogo Educacional, Curitiba, v. 14, n. 41, p. 17-36, jan./abr. 2014.

SAMPAIO, R. F.; MANCINI, M.C. Estudos de revisão sistemática: um guia para síntese criteriosa da evidência científica. Rev. Bras. Fisioter., São Carlos, v. 11, n. 1, p.83-89, jan./fev. 2007.

SILVA, R. A.; SANTOS, R. N. M.; RODRIGUES, R. S. Estudo bibliométrico na base LISA: um enfoque nos artigos sobre surdos. Em Questão, Porto Alegre, v. 17, n. 1, p. 289-304, jan./jun. 2011.

SOARES, M. B.; MACIEL, F. Alfabetização. Brasília: MEC/INEP/COMPED, 2000.

TEIXEIRA, M. L. M.; IWAMOTO, H. M.; MEDEIROS, A. L. Estudos bibliométricos (?) em administração: discutindo a transposição de finalidade. Administração: Ensino e Pesquisa, Rio de Janeiro, v. 14, n. 3, p.423-452, jul./ago./set. 2013.

THORPE, R.; HOLT, R.; MACPHERSON, A.; PITTAWAY, L. Using knowledge within small and medium sized firms: a sys- tematic review of the evidence. International Journal of Management Reviews, v. 7, n. 4, p. 257-281, 2005.

TONELLI, M. J. et al. Produção acadêmica em recursos humanos no Brasil: 1991-2000. Revista de Administração de Empresas, São Paulo, v. 43, n. 1, jan./mar. 2003. 
Entre revisões sistemáticas e bibliometrias: como tem sido mapeada a produção acadêmica em administração no Brasil?

TRANFIELD, D.; DENYER, D.; SMART, P. Towards a methodology for developing evidence-informed management knowledge by means of systematic review. British Journal of Management, v. 14, n. 3, p. 207-222, 2003.

VANTI, N. A. P. Da bibliometria à webometria: uma exploração conceitual dos mecanismos utilizados para medir o registro da informação e a difusão do conhecimento. Ciência da Informação, Brasília, v. 31, n.2, p.152-162, maio/ago. 2002.

VIEIRA, F. G. D. Por quem os sinos dobram? Uma análise da publicação científica na área de marketing do Enanpad. In: ENCONTRO DOS PROGRAMAS DE PÓS-GRADUAÇÃO EM ADMINISTRAÇÃO (ENANPAD), 22., 1998, Foz do Iguaçu (PR). Anais... Foz do Iguaçu: ANPAD, 1998.

\title{
BETWEEN SYSTEMATIC REVIEWS AND BIBLIOMETRICS: HOW HAS THE ACADEMIC PRODUCTION IN ADMINISTRATION BEEN MAPPED IN BRAZIL?
}

\begin{abstract}
Introduction: Considering the progress and expansion of science and technology in recent decades, many are the authors who have discussed the importance of mapping and discussion of academic production in different areas of knowledge. Objective: The purpose of this study was to conduct a discussion about the methodologies used to map the scientific field in the area of Administration. Methodology: We used the database of the Scientific Electronic Library Periodicals (SPELL). Considering the rule of completeness of Bardin (2011), they were discovered and recovered 83 items, ranging from the period 2005-2015. Results: A specific group of researchers has developed the mapping of production in the area since 2005. Multiple databases (events and journals, national and international) are being used by for mapping production. Management has turned to bibliometric studies, however, systematic reviews and systematic reviews remain quite punctual. Conclusion: To carry out the discussion of the methodologies used to map the scientific field in the area of administration was very relevant, mainly because there is, according to the results obtained, a conceptual confusion between bibliometric studies and systematic reviews.
\end{abstract}

Descriptors: Bibliometry. State of art. Knowledge Organization. 


\title{
ENTRE REVISIONES SISTEMÁTICAS Y BIBLIOMETRÍAS: ¿CÓMO SE HA ASIGNADO LA PRODUCCIÓN ACADÉMICA EN ADMINISTRACIÓN EN BRASIL?
}

\begin{abstract}
RESUMEN
Introducción: Teniendo en cuenta el progreso y la expansión de la ciencia y la tecnología en las últimas décadas, muchos son los autores que han discutido la importancia de la cartografía y la discusión de la producción académica en diferentes áreas del conocimiento. Objetivo: Este estudio tuvo por propósito realizar una discusión sobre las metodologías utilizadas para mapear el campo científico en el área de Administración. Metodología: Se utilizó la base de datos de la Biblioteca de Revistas Electrónicas Científicas (SPELL). Teniendo en cuenta la regla de integridad de Bardin (2011), que fueron descubiertos y se recuperaron 83 artículos, que van desde el período 2005-2015. Resultados: Un grupo específico de investigadores ha desarrollado el mapeo de la producción en la zona desde 2005. Las múltiples bases de datos (eventos y revistas, nacionales e internacionales) están siendo utilizados por la producción de la cartografía. La dirección ha vuelto a los estudios bibliométricos, sin embargo, las revisiones sistemáticas y revisiones sistemáticas siguen siendo bastante puntual. Conclusión: Realizar la discusión de las metodologías empleadas para mapear el campo científico en el área de administración se mostró bastante relevante, principalmente porque existe, de acuerdo con los resultados obtenidos, una confusión conceptual entre estudios bibliométricos y revisiones sistemáticas.
\end{abstract}

Descriptores: Bibliometría. Estado de la técnica. Organización del conocimiento. 